\title{
Transition from diagnosis to regular medication use for adults with HIV/AIDS infection
}

\author{
Shou-Yu Wang ${ }^{1}$, Shu-Hui Liu ${ }^{* 2}$, Yu-Ping Huang ${ }^{3}$ \\ ${ }^{1}$ Department of Nursing, Hungkuang University, Taiwan \\ ${ }^{2}$ Department of Nursing, Tzu Hui Institute of Technology, Taiwan \\ ${ }^{3}$ Department of Nursing, National Quemoy University, Taiwan
}

Received: January 1, 2017

DOI: $10.5430 /$ jnep.v7n12p123
Accepted: April 9, 2017

URL: https://doi.org/10.5430/jnep.v7n12p123

\begin{abstract}
Every year, approximately 5 million new HIV and AIDS cases are diagnosed worldwide. With advances in treatment, the lifespan of patients with HIV/AIDS has been extended, with the disease becoming a chronic condition, meaning that long-term care is necessary and complicated. Through effective treatment compliance with high-potency antiviral medication, in viva viral replication can be suppressed; thus, the life expectancy of individual patients can be extended. Therefore, taking medication regularly is crucial for patients. This study employed the grounded theory approach, using a semi structured method to conduct in-depth interviews with 10 participants with HIV/AIDS in Taiwan. Open, axial, and selective coding were used for data analysis. Results: The five categories comprised symptoms resulting from HIV/AIDS, the initial reaction to HIV/AIDS diagnosis, preventative strategies for self-protection, management of interpersonal relationships, and strategies for taking medication regularly. The core category was accepting reality and living with HIV/AIDS. This paper suggests that public education should be used to remove the stigma of HIV/AIDS. Furthermore, combining prevention, education, consultation, counseling, testing, and treatment for effective management can increase medication compliance.
\end{abstract}

Key Words: HIV/AIDS patient, Compliance, Grounded theory, Medication, Qualitative research

\section{INTRODUCTION}

Since 1984, when the first person diagnosed with human immunodeficiency virus (HIV) was reported to be homosexual, gay men have been categorized as a high-risk group for HIV infection. HIV is transmitted in various manners, including unprotected sexual intercourse, blood transfusion, the sharing of intravenous syringes among drug users, and maternal infection. As of 2016, according to a report by the Centers for Disease Control (CDC) in Taiwan, from 1984 to 2016, 31,036 people with HIV/AIDS were present in Taiwan, 93.94\% of whom were male; during this time period, there were 14,934 newly reported patients with acquired immune deficiency syndrome (AIDS) and 5,043 HIV/AIDS-related deaths. ${ }^{[1]}$ The increasing number of patients with HIV/AIDS substantially affects public health and disease control. A minority of patients takes medication regularly and returns for regular follow-up; most do not take medication regularly and discontinue treatment. Currently known anti-HIV medications can improve survival rates and reduce mortality. ${ }^{[2]}$

Because therapy with anti- HIV/AIDS medication is highly complicated and produces various side effects, a substantial proportion of people with HIV/AIDS do not comply with prescribed medication, which is the main cause of treatment

*Correspondence: Shu-Hui Liu; Email: sj911106@yahoo.com.tw; Address: Department of nursing, Tzu Hui Institute of Technology, Taiwan. 
failure. ${ }^{[3]}$ In a study conducted in South Africa, ${ }^{[4]}$ participants were selected from a randomized sample of 607 patients with HIV/AIDS who were interviewed regarding the physiological impact of the disease. A total of 64 symptoms were identified, with an average of 26.1 symptoms per patient. The symptoms might have been directly related to the disease or have been caused by the side effects and complications of anti-HIV/AIDS medications and the benefits has been established especially in the early stage. ${ }^{[5]}$ Social support and stigma exert indirect influences on quality of life when patients take depressive medications. Furthermore, the most effective approach to enhancing health related quality of life among patients who are taking antiretroviral medication is interventions targeting depression. ${ }^{[6]}$

The frequency and intensity of the symptoms caused the HIV/AIDS-infected patients to feel distressed, disrupted their daily routines, and reduced their quality of life, thereby adversely affecting medication compliance. ${ }^{[7,8]}$ The HIV viral load can be reduced by taking medication regularly. One study reported that when the participants took more than $95 \%$ of their regular medication, $81 \%$ of the HIV viral load was suppressed; when $90 \%$ to $95 \%$ of regular medication was taken, only $64 \%$ of the viral load was suppressed. ${ }^{[9]}$ Hence, for an effective therapeutic effect, patients with HIV/AIDS should take $100 \%$ of their regular medication. Depressive symptoms and anxiety are known to cause premature death among patients with HIV/AIDS. ${ }^{[4]}$ Moreover, the quality of life for people living with HIV/AIDS may be substantially influenced by HIV/AIDS stigma. ${ }^{[10]}$

Most patients with HIV/AIDS tend to focus on the medical treatment of AIDS symptoms and are reluctant to share their feelings with health care professionals (HCPs).$^{[7,11]}$ The inability of HCPs to promptly detect psychological symptoms and mood changes might affect the regularity of patients' medication intake and cause further deterioration of their condition. A survey of patients with HIV/AIDS between 1995 and 2009 revealed that $69 \%$ of patients accepted treatment after their diagnosis was confirmed. However, the follow-up rate decreased from $71 \%$ to $27 \%$ during the initial 6 months after diagnosis. This decrease in the low follow-up rate and a gradual decline in the survival rate were confirmed by Marks et al. (2010). ${ }^{[12]}$ The Internet could be used to effectively disseminate relevant medical information to people and increase their willingness to seek treatment. ${ }^{[13]}$ Furthermore, one study that investigated Chinese college students who were enrolled in an HIV/AIDS-related education program determined that crucial information for developing more differentiated intervention strategies specific to gender for HIV/AIDS and sexually transmitted infection education programs are essential. ${ }^{[14]}$ In addition, because HIV viral loads can be reduced through regular medication, determining effective methods of increasing the medication compliance motivation of patients with HIV/AIDS has become crucial.

Patients with HIV/AIDS experience physical and psychological pain as well as social stigmatization. Furthermore, their family members, who act as caregivers, are likely to be highly depressed because they experience pressure from the fear of being infected. ${ }^{[15]}$ The shock of a confirmed HIV/AIDS diagnosis is often unbearable for people and contributes to the adverse effects of their physical symptoms. Patients with HIV/AIDS typically experience a period of denial and must learn to accept their condition and avoid infection. In addition, they gradually adapt to the side effects of drug cocktails to reduce the viral load, prolong their lives, protect their immune system, and prevent opportunistic infection. Furthermore, patients with HIV/AIDS undergo behavioral changes, accept medication, take medication regularly, and follow up regularly to improve their quality of life and seek the true meaning of life. ${ }^{[16-18]}$ Therefore, this study explored the transition from diagnosis to regular medication use for HIV/AIDS infected adults.

\section{METHODS}

Grounded theory was employed in this study. Data were collected and analyzed thoroughly to obtain a deeper insight into the study phenomenon. ${ }^{[19]}$ Through one-on-one semi structured and in-depth interviews, this study explored the transition from diagnosis to regular medication use for HIV/AIDS infected adults. The semi structured interview questions included "Please tell me what AIDS is"; "What was your experience when you were diagnosed with AIDS?"; "How did you get used to the side effects of the medication?"; and "How did you manage to take your medication in a regular manner during your treatment journey?"

The concepts determined in this study were derived from the data according to the grounded theory method and analysis. The concepts were subsequently interlinked to establish categories and subcategories. Through the direct and indirect impact of certain actions and interactions on the participants, a direct association with the study phenomenon was established. ${ }^{[20]}$ The study phenomenon in this study is the transition from diagnosis to regular medication use for HIV/AIDS infected adults.

\subsection{Ethical considerations}

The study protocol was approved by the institutional review board of a regional teaching hospital in Taiwan (IRB No: 100011), and informed consent was obtained from the participants before the interviews. A strict confidentiality protocol was followed, and the participants remained anonymous. Fur- 
thermore, the interviews were conducted in an independent meeting room to ensure that they could be completed without interruption and in a comfortable setting. In addition, the first author conducted the interviews after establishing a rapport with the participants. Furthermore, the researchers transcribed the interviews verbatim and made notes during the analysis. All raw data, analysis results, and letters of consent are available for review.

\subsection{Participants and data collection}

The data collection of this study was carried out during Aug. 2012 to Jan. 2013. One of the researchers involved was an HIV/AIDS patient manager in a hospital in Taiwan. Each participant was interviewed once; the inclusion criteria were as follows: (a) age > 20 years; (b) diagnosis of HIV/AIDS; and (c) consent to record the interview. The study aims were explained to the participants before the interviews. To protect the privacy of the participants, the interviews were conducted in an independent room and pseudonyms were used, such as Mr. Ho, to protect the participants' confidentiality and anonymity. Ten participants were recruited over 6 months. Each interview lasted for an average of 45 minutes. The average age of the participants was 39 years, and all of them had received regular medication for 2-4 years.

After the data of one participant were collected, they were immediately analyzed before the next participant was interviewed; thus, the data were collected and analyzed simultaneously. Interviews were conducted until no new dimensions emerged and the data were saturated.

\subsection{Data analysis}

Each interview recording was transcribed verbatim and thoroughly analyzed to establish some key phrases and concepts. During data analysis, open coding and axial coding was used to identify and label categories, thereby connecting and establishing dimensions, categories, and subcategories. ${ }^{[21]}$ The procedure is as follows: First, the transcript is read after the tape is recorded, followed by transcript analysis. Next, progressive stepping analysis is used to divide the short phrases. These ideas are gradually categorized into similar phrases, concepts, and the same phenomena. Furthermore, concepts were identified by grouping phrases with the same coding. The authors then named different concepts and further integrated into categories. In addition, the categories and subcategories were linked through repeated questioning, and the differences of each category were established. ${ }^{[21-23]}$

Continuous comparisons and asking question were used to compare data during data analysis, so that the relationships between categories and subcategories were well established (see Table 1). Memos were also written regarding the key related concepts revealed during data analysis. In summary, during the data collection phase of the study, a wealth of information was analyzed to establish dimensions and categories that would be further analyzed to finally present a story line. In summary, data collection involved analyzing information to establish dimensions and categories that were subsequently further analyzed to present the storyline of the treatment journey of the participant.

Table 1. The relationships between categories and subcategories

\begin{tabular}{|c|c|c|}
\hline Subcategories & Categories & Core category \\
\hline 1) HIV symptoms & Comprised symptoms resulting from & \multirow{11}{*}{$\begin{array}{l}\text { Accepting reality and living with } \\
\text { HIV/AIDS }\end{array}$} \\
\hline 2) AIDS symptoms & HIV/AIDS & \\
\hline 1) Precaution & The initial reaction to HIV/AIDS & \\
\hline 2) Behavior change & diagnosis & \\
\hline 1) Depressed and helpless & \multirow{2}{*}{ Preventative strategies for self-protection } & \\
\hline 2) Coming to an end & & \\
\hline 1) Deciding whether to disclose the diagnosis & \multirow{2}{*}{$\begin{array}{l}\text { Management of interpersonal } \\
\text { relationships }\end{array}$} & \\
\hline 2) Fearing discovery of their condition: & & \\
\hline 1) Adapting to the side effects & \multirow{3}{*}{ Strategies for taking medication regularly } & \\
\hline 2) Reminding each other & & \\
\hline 3) Self-management & & \\
\hline
\end{tabular}

\section{RESULTS}

\subsection{Characterization of participants}

Our participants were aged between 23 and 61 years. The average age of the participants was 39 years, and all of them had received regular medication for 2-4 years. In addition, this

Published by Sciedu Press study involved seven male participants and three female participants. According to Taiwanese statistics on patients with AIDS, more of these patients are male than female (13:1), which is consistent with the CDC data for 2014. Because only three female participants were included in this study, the results may not be representative of medication compliance 
among women with HIV/AIDS. The participants in this study had been treated for HIV for 4-5 years. Moreover, future studies should be conducted on patients with HIV who have regularly used medication over a long period (for example, more than 5 years) to obtain more comprehensive data (more detailed participant demographics are provided in Table 2).

\subsection{Symptoms resulting from HIV/AIDS}

The participants typically initially experienced physical discomfort because of opportunistic infections, which were mostly limited to the respiratory and gastrointestinal tracts. Symptoms included fungal growth in the oral cavity, weight loss, coughing, and fever. These symptoms persisted for prolonged periods and were incurable. As one participant, Mr. Han, said, "I thought it was some gastrointestinal reflux initially ... breathing with difficulty, intermittent coughing, followed by persistent coughing. I could see some whitish material in my mouth, and the doctor said it looked like that thing." In other cases, participants consulted doctors because of symptoms of sexually transmitted diseases such as syphilis and herpes. After receiving treatment for a limited duration, the doctors suggested HIV tests, after which the diagnosis was confirmed. As Mr. Lu said, "Because it looked like syphilis on my hands then ... That's right! At that time, I thought it was just some rash ... I went to see a doctor, and I was diagnosed with AIDS!"

Table 2. The participants' dempgraphics

\begin{tabular}{|c|c|c|c|c|c|c|c|c|c|}
\hline Participant & Age & Sex & Marriage & Education & Religion & $\begin{array}{l}\text { Family } \\
\text { informed }\end{array}$ & Sexuality & $\begin{array}{l}\text { Regular } \\
\text { medication } \\
\text { (year) }\end{array}$ & Occupation \\
\hline Но & 38 & Male & No & College & Taoism & Mother & Androgyny & 4 & $\begin{array}{l}\text { Pubic } \\
\text { servant }\end{array}$ \\
\hline $\mathrm{Lu}$ & 33 & Male & No & $\begin{array}{l}\text { Junior } \\
\text { college }\end{array}$ & No & No & Homo & 2 & $\begin{array}{l}\text { Catering } \\
\text { industry }\end{array}$ \\
\hline Shih & 44 & Male & No & $\begin{array}{l}\text { Vocational } \\
\text { school }\end{array}$ & No & No & Hetero & 4 & Labor work \\
\hline Hang & 33 & Male & No & $\begin{array}{l}\text { Junior } \\
\text { college }\end{array}$ & Taoism & No & Homo & 2 & Labor work \\
\hline Chiang & 56 & Female & Widowed & $\begin{array}{l}\text { Elementary } \\
\text { school }\end{array}$ & No & No & Hetero & 2 & Labor work \\
\hline Shan & 49 & Female & Yes & $\begin{array}{l}\text { Junior } \\
\text { college }\end{array}$ & Taoism & $\begin{array}{l}\text { Yes } \\
\text { Spouse }\end{array}$ & Hetero & 2 & Labor work \\
\hline Han & 30 & Male & No & $\begin{array}{l}\text { Junior } \\
\text { college }\end{array}$ & No & No & Homo & 2 & No \\
\hline Yang & 22 & Male & No & College & No & $\begin{array}{l}\text { Yes } \\
\text { Mother }\end{array}$ & Homo & 2 & Student \\
\hline Kong & 61 & Male & Yes & $\begin{array}{l}\text { Elementary } \\
\text { school }\end{array}$ & Taoism & $\begin{array}{l}\text { Yes } \\
\text { Spouse }\end{array}$ & Hetero & 4 & Labor work \\
\hline Tsao & 28 & Female & No & Junior school & Taoism & $\begin{array}{l}\text { Yes } \\
\text { Spouse }\end{array}$ & Hetero & 4 & No \\
\hline
\end{tabular}

\subsection{Initial reaction to HIV/AIDS diagnosis}

Upon diagnosis, the participants felt depressed, helpless, and that their world was "breaking apart" and life was "coming to an end." For example, Mr. Shih said "I wondered how I could be so unlucky. It was just that one time ... I couldn't accept the truth at first ... [I felt] completely hopeless, it was like the end of the world." In contrast to such responses, one participant simply accepted the fact and the suggested therapy. Mr. Ho stated 'I didn't even think about it because what is the point? I didn't even think about it then ... After all, I already have it. He [the doctor] said the disease had progressed, so I had to take medicine. I didn't think much 126 about it because it's pointless." As these reactions indicate, upon diagnosis, the participants made their own assessments of the disease and responded in various manners.

\subsection{Preventative strategies for self-protection}

According to our results, the participants adopted measures to protect their family members and others from their disease. Several participants began taking such precautions and underwent behavioral changes immediately after the symptoms first appeared. They questioned their behavior that caused them to contract the virus, for example, their sexual behavior and hygienic habits. As Mr. Lu stated, “I don't want to get 
other people into trouble ... I want to protect them ... I started using condoms. . " Mr. Chang said "I try my best not to infect others, so I take as many precautions as possible. I don't want to infect anybody..." Mr. Shih felt that he had to be strong-willed to fight the disease and ultimately changed his lifestyle: "I stopped having late nights ... My condition will deteriorate if I abuse my body... you won't be able to fight it, so I'd better take good care of my body. I feel that there's still some hope."

\subsection{Management of interpersonal relationships}

The responses of the participants regarding interpersonal relationships were mainly related to deciding whether to disclose their diagnosis and fearing discovery of their condition. In this study, the participants chose not to reveal the truth or to inform only close friends and relatives. Subsequently, fearing the revelation of their condition, they acted to keep their diagnosis confidential. Mr. Chang said "I've got HIV ... My family knew nothing about it ... I'm afraid that my wife couldn't take it... I've brought it onto myself, and I don't want anybody close to me to feel pressure because of this."

Furthermore, the participants believed that HIV/AIDS was a socially unacceptable disease, and they did not want their reputation to be tarnished by the revelation of their condition. Mr. Kong said "I do not dare let other people know ... People would laugh at me ... scared of being infected... They'd be scared to death; nobody dares to breathe a word about their HIV ... because this disease is infectious ... Before I would even start, people would have already run away." The participants preferred not to tell others, including their family members and colleagues. Although they continued visiting doctors, they continued to conceal their diagnosis. For example, Mr. Shih said "I threw away the boxes [that the medication came in] and just took the bottles home... But I will burn them, together with the receipts, because it's not nice to let other people see it ... They might talk negatively about me behind my back." The participants feared that their condition would be revealed, but by concealing their diagnosis, felt secure enough to continue their interpersonal relationships.

\subsection{Strategies for taking medication regularly}

According to the participants, taking medication regularly required adapting to the resultant side effects. Furthermore, the participants observed improvements in their condition and returned for follow-ups and to continue medication use. Moreover, they sought various approaches to complying with medication regimens and eventually engaged in selfmanagement to prolong their lives.

Published by Sciedu Press
(1) Adapting to the side effects: The participants related how they adapted to the side effects. For example, Mr. Shih said "I'll take it (medication) if it's effective... I'd try to get over the diarrhea ... Probiotics were effective, so I would drink them as much as possible, and the diarrhea would slowly go away." Another participant, Ms. Shen said "I felt really warm after taking the medication at night, just like during menopausal flashes; it was very uncomfortable. How did I manage? I thought of some ways. I went to bed straightaway after taking the medication, or just switched on the air-conditioning or took a cold shower and I would feel better." Several participants viewed the medications as vitamins. They regarded HIV/AIDS as a chronic disease and adapted by taking the medication regularly. Furthermore, taking the medication enabled the participants to remain healthy, thereby suppressing the virus.

(2) Reminding each other: The participants in this study included couples. The partners reminded each other to take the medication regularly and attend follow-up hospital visits. Mr. Lu said "My partner is also an AIDS victim. If I remember that she hasn't taken her medication, I remember that I need to take medication, too ... So we'll remind each other." The determination of participants to take their medication regularly was strengthened after a family member learned of their condition. For example, Mr. Chang said "My daughter knew about my condition. Before she got married, she would always check my follow-up record and remind me to go to the hospital. She's married now, but she'll still call to remind me of the follow-up visits." The family members of several participants accompanied them on follow-up visits, cared for them, and reminded them to take medication. These actions were valuable to the participants during their adaptive process from diagnosis to regular medication use.

(3) Self-management: The participants stated that stopping the medication might lead to viral resistance to the drugs; $\mathrm{Mr}$. Shih said "I won't forget, and I won't stop taking the medication ... because there will be drug resistance ... then the virus will become unstoppable ... To me, taking medication is just a habit." The participants documented every blood test, because they believed that complying with their medication regimens effectively suppressed the virus and increased their lymphocyte count and immunity. This enabled them to control their condition and keep the virus count within safe limits. The final result of these self-management strategies was delaying the onset of complications. For example, Ms. Shen said "Every time they take my blood sample and I see a rise in immunity, I become more confident ... As long as I keep regularly taking the medication in the long term, my condition will be under control." 


\subsection{Core category: Accepting reality and living with HIV/AIDS}

In summary, in this study, when the participants transitioned from the symptomatic or asymptomatic period to the initial post diagnosis stage, they experienced various emotions. Several participants entered denial or had suicidal thoughts; however, after passing this stage, they began to consider taking protective measures. They were required to decide whether to tell their close friends and family about their condition, which would likely affect their interpersonal relationships. The participants overcame these and other problems, and they adapted to the side effects of the medication and attended follow-up hospital visits. Although they believed that HIV/AIDS was incurable, they preferred to take their medication regularly to prolong their lives. For example, $\mathrm{Mr}$ Han said "I want to live, so I have to follow up ... because, without the medication, my viral counts will escalate and CD4 counts will decline. So I tell myself that if I don't want to live, I can just stop getting the medication." The participants felt as though they were living life normally without any help from their family, as highlighted by Mr. Shih: "Maybe my family will need to take care of me later... I must protect myself and make my body and antibodies OK... I am leading a normal life at this point."

Furthermore, the participants felt that they could live with AIDS for the remainder of their lives. Mr. Han said "Actually, I live from day to day. Regardless of the decision [to take the medication or not], people need to work, or get married and start a family... Just do what you feel like doing." They believed that taking their medication regularly would return them to health. As Mr. Chang said, “Doesn't affect my job ... Now I'm OK, just like back in those carefree days. Everything has gone back to normal after taking the medication." The participants experienced numerous emotional changes after diagnosis. They were required to take medication regularly and conceal the truth to preserve their reputations. In addition, they made the difficult decision of whether to tell their close friends and relatives about their condition. The participants maintained their health by regularly taking medication and maintained or resumed a semblance of normality so that they could maintain an active and normal social life. This process is shown in Figure 1.

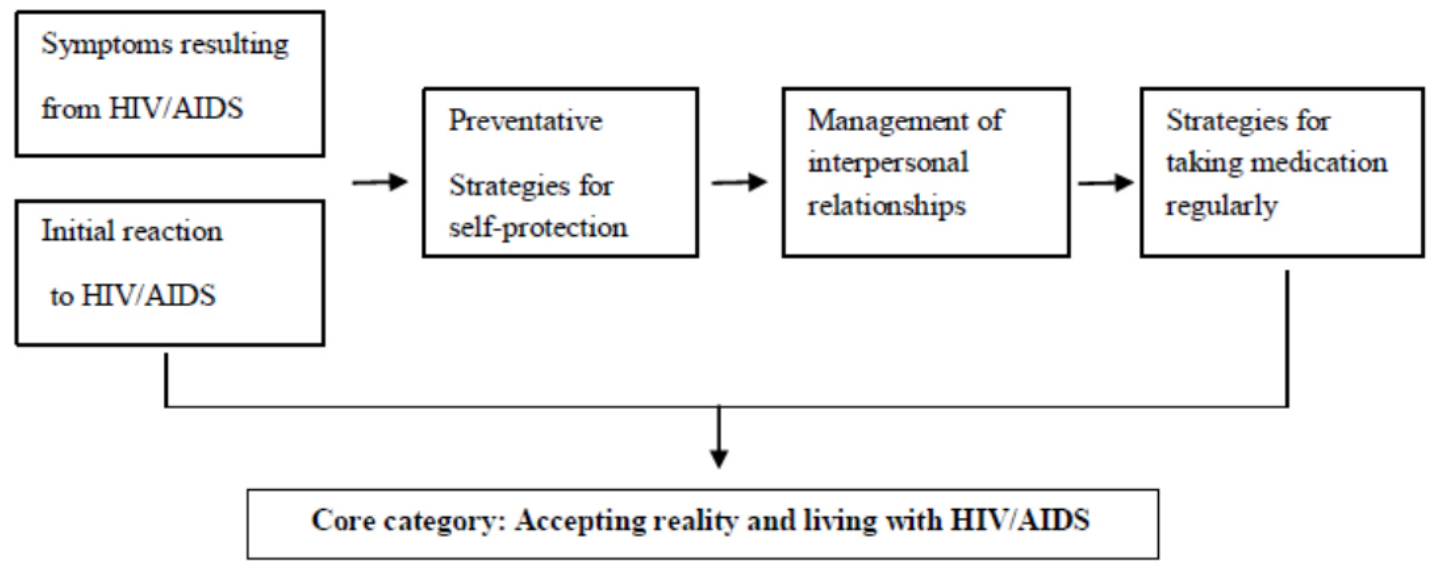

Figure 1. The transition process from diagnosis to regular medication for HIV/AIDS infected adult patients

\section{DisCUSSION}

\subsection{Symptoms resulting from HIV/AIDS}

Currently more than 35 million people living with HIV worldwide, Diagnostics of HIV and monitoring antiretroviral therapy (ART) are critical. ${ }^{[24]}$ One study revealed that women with HIV primarily acquired HIV through unsafe sexual activities. ${ }^{[25]}$ Most of the participants interviewed in this study discovered that they had HIV/AIDS after visiting a hospital because of symptoms caused by weakened immunity and opportunistic infections. A questionnaire specifically for people who practiced unprotected sexual intercourse or had multiple sexual partners revealed that the respondents lacked the correct attitude and necessary knowledge to avoid HIV infection. Furthermore, the participants believed that continual education about HIV/AIDS and safety measures would be highly relevant for students and working-class people. ${ }^{[26]}$

\subsection{Initial reaction to HIV/AIDS diagnosis}

According to previous studies, patients with HIV/AIDS who experience the uncertainty of waiting for diagnosis confirmation and then must decide whether to reveal their condition often experience considerable trauma and pressure in the early stages. An assessment of psychological problems is difficult, and insight into the needs of patients with HIV/AIDS can be gained only after trust has been established. However, this insight is essential for determining a patient's needs 
and appropriate corrective measures. Furthermore, feelings of uncertainty, denial, anger, and all other negative emotions must be converted into positive emotions for patients to seek HIV/AIDS information. ${ }^{[27]}$ Hence, a positive rapport must be established before assessing the healthcare needs of a patient with HIV/AIDS. Our study determined that the participants experienced helplessness, denial, despair over contracting an incurable disease, and suicidal thoughts. Upon a positive diagnosis, a patient with HIV/AIDS is typically overwhelmed with anxiety, depression, social isolation, or suicidal thoughts. ${ }^{[28,29]}$ One study also determined that the adolescents were inadequately informed by their parents about sex and AIDS and provided negative judgment regarding HIV. ${ }^{[30]}$

\subsection{Management of interpersonal relationships}

People with HIV/AIDS were usually perceived as alien and assumed as drug users, homosexuals, or debauched. ${ }^{[31]}$ One study indicated that young women with HIV worried about disclosing their condition and then suppressed their cognitive and emotional expression because of the stigma associated with HIV/AIDS. ${ }^{[32]}$ The fact that most of the participants in this study were unwilling to inform their family members and close friends about their condition is understandable. These participants struggled emotionally because they were afraid that their family members and close friends would not forgive them. They also did not want to give up their lifestyle. However, some of the participants still informed family members about their condition. Furthermore, at the time of the interviews, the participants were newly diagnosed, and their lives were not threatened by their symptoms. However, the participants adopted the principle of living day by day and did not make any long-term plans. Because the participants had been diagnosed with HIV/AIDS 4-5 years earlier, they began to think about changing their lifestyles. Furthermore, they were mostly satisfied with their health and did not worry about their health deteriorating in the future.

The participants felt that HIV/AIDS was considerably worse than cancer; therefore, they preferred not to disclose their condition. $45.3 \%$ of patients with HIV/AIDS in Taiwan did not reveal their condition to friends and relatives because of unfriendly attitudes toward the disease. ${ }^{[17]}$ Because of myths \& misconceptions of HIV/AIDS, the stigma that surrounds people living with HIV/AIDS has shown little sign of diminishing and negative perceptions still persist. ${ }^{[31]}$ This is the reason that most patients with HIV/AIDS choose not to reveal their condition. In this study, the participants purposely kept themselves at a distance from society and chose not to tell their friends and relatives about their own condition.

Published by Sciedu Press

\subsection{Strategies for taking medication regularly}

According to one study that was conducted in Taiwan, the main reason for patients with HIV/AIDS not taking medication regularly is fear of medication affecting their lives. In addition, they worry that the medication might induce negative emotions such as anxiety and fear, affect their social interaction, and reveal that they have HIV/AIDS. ${ }^{[33]}$ The thoughts of patients with HIV/AIDS about taking medication regularly and the obstacles to medication compliance should be known by HCPs, who should also understand patients' reasons for accepting or refusing treatment. The participants in this study believed that regularly taking medication can effectively suppress the virus and reduce resistance to drugs. As they take medication over a long period, their condition can be controlled. In 2012, more than $86 \%$ of patients with HIV/AIDS in Taiwan sought medical advice, and the mortality rate decreased sharply from $28.6 \%$ in 1997 to $0.71 \%$ in 2012. ${ }^{[34,35]}$ In recent years, the use of drug cocktails has prolonged the lives of patients with HIV/AIDS. In Taiwan, the CDC began implementing a case management plan in 2007. In addition, one study showed that medication compliance and maintaining a positive self-image were greatly augmented when adult HIV/AIDS patients remained close to their family. ${ }^{[36]}$

\subsection{Core category: Accepting reality and living with HIV/AIDS}

In this study, some of the participants indicated that taking medication outside the home was inconvenient because doing so risked others learning about their condition. The participants concealed their medication use and disposed of the medication boxes. According to one study, medication functioned as a motivator, inducing HIV/AIDS patients to follow their regimens. ${ }^{[37]}$ A cohort study in Denmark also determined that the average survival of patients with HIV/AIDS had increased to 32.5 years by the end of the drug cocktail therapy era (2000-2005). ${ }^{[38]}$ Hence, HCPs must attempt to resolve patient concerns and address their emotional changes to build a trust-based relationship that motivates the patients to return for medication and follow-ups. The participants in this study believed that taking their medication regularly would return them to health. As Mr. Chang said, "Doesn't affect my job... Now I'm OK, just like back in those carefree days. Everything has gone back to normal after taking the medication."

\section{Conclusion}

This study involved conducting in-depth interviews and collecting data from 10 adults with HIV/AIDS regarding the transition from diagnosis to regular medication use. We determined that the participants sought medical advice in 
the symptomatic and asymptomatic phases. Furthermore, upon receiving a confirmed diagnosis, several participants began taking protective measures. Late HIV diagnosis will result in lost opportunities for preventing the spread of the infection. ${ }^{[39,40]}$ In addition, people living with HIV/AIDS were reluctant to disclose their condition to others because they feared exposure. Moreover, they adapted to the side effects of the medications, self-managed their conditions, and regularly sought medication and follow-ups. Finally, the participants adopted a positive attitude, accepted their situation, and continued to lead a normal life.

\section{Implications and contributions of this study}

This study showed that the participants were more motivated to return regularly for medication and follow-ups when they received support from their family. In addition, this support aided the participants in adapting to the diagnostic process.
Regarding education policies, this study indicated that most of the participants did not reveal their condition because of the risk of social exclusion. For people who are homosexual, having HIV/AIDS is likely to worsen the existing discrimination that they face because of their sexuality. Hence, in addition to caring for patients with HIV/AIDS, governments should enhance HIV/AIDS education to prevent stigmatization.

\section{ACKNOWLEDGEMENTS}

We thank all the participants for sharing their experiences and our colleagues from the Infectious Diseases Department of the hospital at which the study was conducted for their invaluable support and suggestions.

\section{CONFLicts OF InTEREST Disclosure}

The authors declare that there is no conflict of interest.

\section{REFERENCES}

[1] Centers for Disease Control: 2016 Statistics monthly report: HIV/AIDS, March5. [Internet]. Taiwan, R.O.C.; [cited 2016 Jan] Available from: http://www.cdc.gov.tw/public/Attachment $/ 1398463971 / \mathrm{xls}$

[2] Luo YJ. Factors dangerous of delayed diagnosis from Taiwan gay HIV infection. Report of epidemic situation. 2008; 24(11): 813-825.

[3] Gu LB, Yan BM, Fu LA, et al. Taiwan's PLHIV needs assessment. Taiwan Journal of Public Health. 2006; 26(1): 38-48.

[4] Peltzer K, Phaswana-Mafuya N. The symptom experience of people living with HIV and AIDS in the Eastern Cape, South Africa. BMC Health Services Research. 2008; 8: 271. PMid:19102765 https://doi.org/10.1186/1472-6963-8-271

[5] Huang UT. Challenges and responses in providing palliative care for people living with HIV/AIDS. International Journal of Palliative Nursing. 2013; 19(5): 218-25. PMid:23971305 https ://doi .org/ 10.12968/ijpn.2013.19.5.218

[6] Li X, Li L, Wang H, et al. Mediation analysis of health-related quality of life among people living with HIV infection in China Nursing and Health Sciences. 2015; 17: 250-256. PMid:25496799 https://doi.org/10.1111/nhs.12181

[7] Johnson MO, Folkman S. Side effect and disease related symptom representations among HIV+ adults on antiretroviral therapy. Psychology Health \& Medicine. 2004; 9(2): 139-148. https: //doi.org/10.1080/13548500410001670672

[8] Johnson MO, Catz SL, Remien RH, et al. Theory guided, empirically supported avenues for intervention on HIV medication nonadherence: Findings from the Healthy Living Project. AIDS Patient Care STDS. 2003; 17(12): 645-656. PMid:14746658 https : //doi.org/10.1089/108729103771928708

[9] Paterson DL, Swindells S, Mohr J, et al. Adherence to protease in hibitor therapy and outcomes in patients with HIV infection. Annals of Internal Medicine. 2000; 131: 21-30. https ://doi .org/10.7 326/0003-4819-133-1-200007040-00004

[10] Holzemer WL, Human S, Arudo J, et al. Exploring HIV stigma and quality of life for persons living with HIV infection. Journal of the As- sociation of Nurses in AIDS Care. 2009; 3: 161-168. PMid:19427593 https://doi.org/10.1016/j.jana.2009.02.002

[11] Eller L S, Corless I, Bunch EH, et al. Self-care strategies for depressive symptoms in people with HIV disease. Journal of Advanced Nursing. 2005; 51(2): 119-130. PMid:15963183 https: //doi.org/10.1111/j.1365-2648.2005.03474.x

[12] Marks G, Gardner LI, Craw J. Entry and retention in medicinal care among HIV-diagnosed persons: a meta-analysis. AIDS. 2010; 24: 2665-2678. PMid:20841990 https://doi .org/10.1097/QA D. $0 \mathrm{~b} 013 \mathrm{e} 32833 \mathrm{f} 4 \mathrm{~b} 1 \mathrm{~b}$

[13] Guo YR, Goh DHL. "I Have AIDS": Content analysis of postings in HIV/AIDS support group on a Chinese micro blog. Computers in Human Behavior. 2014; 34(4): 219-226. https ://doi.org/10.1 $016 / j . c h b .2014 .02 .003$

[14] Tung WC, Serratt TD, Lu M. Evidence-based HIV pilot program for Chinese college students: Differences by gender. Nursing and Health Sciences. 2015; 17: 263-268. PMid:25494686 https ://doi .org/ $10.1111 / \mathrm{nhs} .12183$

[15] Lin SH, Xie SZ. Nursing experience that take care of a sexual infection AIDS cases. Chang Gung Journal of Nursing. 2009; 20(4): 540-550.

[16] Qiu PY, Guo SA. AIDS patients the diagnosis of mental processes and coping behaviors. Hang Gung Journal of Nursing. 2001; 12(3): 189-199.

[17] Lin BS. 2014 AIDS is not a disease, Disease is the human rights to educate March 9. 2007. Available from: http://enews . ccu.edu . tw/modules/news/article.php?storyid=5210

[18] Kasatpibal N, Viseskul N, Srikantha W, et al. Effects of Internetbased Instruction on HIV Prevention Knowledge and Practices among Men Who Have Sex with Men. Nursing and Health Sciences. 2014; 16(4): 514-520. PMid:24645824 https://doi.org/10.1111/nh s. 12135

[19] Strauss A, Corbin J. Basics of qualitative research: Techniques and procedures for developing grounded theory. Thousand Oaks, CA: Sage; 1990. 
[20] Glaser BG, Strauss AL. The Discovery of grounded theory: Strategies for qualitative research. New York: Aldine; 1967.

[21] Strauss A, Corbin J. Basics of qualitative research: Techniques and procedures for developing grounded theory (2nd ed.). Thousand Oaks, CA: Sage; 1998.

[22] Eaves YD. A synthesis technique for grounded theory data analysis. Journal of Advanced Nursing. 2001; 35(5): 654-663. PMid:11529967 https://doi.org/10.1046/j.1365-2648.2001.01897.x

[23] Wang SY, Windsor C, Yates P. Introduction grounded theory method. Journal of Nursing. 2012; 59(1): 90-95.

[24] Shafiee H, Wang SQ, Inci F, et al. Emerging technologies for pointof-care management of HIV infection. Annual Review of Medicine. 2015; 66: 387-405. PMid:25423597 https ://doi .org/10.1146/ annurev-med-092112-143017

[25] Domanska CA, Teitelman AM. Factors that affect acceptance of HIV microbes among women. Collegian. 2012; 19: 23-32. https : //doi.org/10.1016/j. colegn.2011.09.006

[26] Petros P. Risk perception, HIV/AIDS related knowledge, attitude and practice of the university community: The case of Ethiopian Civil Service College. HIV \& AIDS Review. 2014; 13(1): 26-32. https://doi.org/10.1016/j.hivar.2013.12.001

[27] Guo JT, Lai PY, Ko NY. Early diagnosis of HIV disease of young students in response to the impact. Veterans General Journal of Nursing. 2006; 23(1): 35-43.

[28] Li MP. The impact of the plight of gay youth and HIV infection in the early infection. AIDS Care. 2011; 77: 16-25.

[29] Brushers DE, Neidig JL, Russell JA. The medical personal and social causes of uncertainty in HIV illness. Issues in Mental Health. 2003; 24: 497-522. https://doi.org/10.1080/01612840305292

[30] Meechamnan C, Fongkaew W, Chotibang J, et al. Do Thai parents discuss sex and AIDS with young adolescents? A qualitative study. Nursing and Health Sciences. 2014; 16: 97-102. PMid:23692292 https://doi.org/10.1111/nhs.12072
[31] Pickles D, King L, Lacey S. Culturally construed beliefs and perceptions of nursing students and the stigma impacting on people living with AIDS: A qualitative study. Nurse Education Today. 2017; 49: 39-44. PMid:27886625 https://doi.org/10.1016/j.nedt .2016 .11 .008

[32] East L, Jackson D, O'Brien L, et al. Stigma and stereotypes: Women and sexually transmitted infections. Collegian. 2012; 19: 1521. PMid:22482278 https://doi .org/10.1016/j. colegn. 201 1.10 .001

[33] Xie JY, Ko NY. Enhanced HIV infection taking highly active antiretrieval drugs treatment motivation. AIDS Care. 2010; 73: 30-36.

[34] Ko NY, Lai YY, Lai PY, et al. Indicators of quality of care for HIVinfected persons. AIDS Care. 2010; 73: 15-20.

[35] Chen CH. Epidemiological analysis of Taiwan's aging HIV infection. AIDS Care. 2013; 85: 8-18.

[36] Shittu RO, Issa BA, Olanrewaju GT, et al. Family dysfunction among depressed HIV/AIDS patients on HAART, in a secondary health institution, in north central Nigeria. HIV \& AIDS Review. 2014; 13(2): 33-39. https://doi.org/10.1016/j.hivar.2014.02.005

[37] Mohammadpour A, Yekta ZP, Nasrabadi ARN. HIV-infected patients' adherence to highly active antiretroviral therapy: A phenomenological study. Nursing and Health Sciences. 2010; 12: 464-469. PMid:21210925 https://doi .org/10.1111/j.1442-2018.20 10.00560.x

[38] Lohse N, Hansen AB, Pedersen G. Survival of Persons with and without HIV Infection in Denmark, 1995-2005. Annals of Internal Medicine. 2007; 146: 87-95. PMid:17227932 https://doi.org/ 10.7326/0003-4819-146-2-200701160-00003

[39] Liu XY, Ko NY, Lai YY, et al. A target and quality of care for HIVinfected persons. AIDS Care. 2010; 73: 15-20.

[40] Taborelli M, Virdone S, Camoni L, et al. The persistent problem of late HIV diagnosis in people with AIDS: a population-based study in Italy, 1999-2013. Public Health. 2017; 142: 39-45. PMid:28057195 https://doi.org/10.1016/j.puhe.2016.10.009 